\title{
ANTIBACTERIAL EFFICACY OF GRAPE SEED EXTRACT CONTAINING 2.9\% TANNIN AGAINST ENTEROCOCCUS FAECALIS BIOFILM
}

\author{
SHELVY SOETANTO, ENDANG SUPRASTIWI*, DINI ASRIANTI \\ Department of Conservative Dentistry, Faculty of Dentistry, Universitas Indonesia, Jakarta, 10430, Indonesia. Email: esuprastiwi@yahoo.co.id \\ Received: 27 August 2018, Revised and Accepted: 07 February 2019
}

\begin{abstract}
Objective: The aim of this study was to observe the antibacterial efficacy of grape seed extract (GSE) against Enterococcus faecalis biofilm.

Methods: A biofilm of E. faecalis American Type Culture Collection (ATCC) 29212 strain was prepared using sterile cellulose nitrate filter membrane incubated on brain heart infusion agar at $37^{\circ} \mathrm{C}$ for $72 \mathrm{~h}$ under aerobic condition. Each membrane containing $E$. faecalis biofilm was added to three tubes of phosphate-buffered saline (control), three tubes of GSE, and three tubes of $2 \%$ clorhexidine. The number of viable DNA cells was measured using real-time polymerase chain reaction. The data were statistically analyzed using non-parametric Kruskal-Wallis test and Mann-Whitney U-test.
\end{abstract}

Results: GSE had antibacterial efficacy against $E$. faecalis biofilm. The difference in the amount of $E$. faecalis DNA between all groups was statistically significant $(\mathrm{p}=0.05)$.

Conclusion: GSE has antibacterial efficacy against E. faecalis biofilm.

Keywords: Grape seed extract, Biofilm, Enterococcus faecalis.

(C) 2019 The Authors. Published by Innovare Academic Sciences Pvt Ltd. This is an open access article under the CC BY license (http://creativecommons. org/licenses/by/4. 0/) DOI: http://dx.doi.org/10.22159/ijap.2019.v11s1.165

\section{INTRODUCTION}

The aim of root canal treatment is to prevent the progression of infection to the periapical tissue; however, the aim of periapical disease treatment is to create the ideal conditions for the disease to heal [1]. This goal can be achieved through instrumentation, disinfection, and obturation of the root canal. As the root canal has a complex anatomy, root canal preparation using mechanical instrumentation only partially eliminates the bacteria in the root canal [2]. It is expected that the combination of endodontic instrumentation and antibacterial agents can eliminate all infections on the periapical tissue [3].

Endodontic infections are polymicrobial. These microorganisms are usually opportunistic pathogens that are beneficial under normal conditions but can be pathogenic when they reach the pulp or periapical tissue [4]. The microorganisms involved in endodontic infections are bacteria, fungi, archaea, and viruses. Candida albicans is a common fungal species found in the oral cavity. According to a recent study, C. albicans was found in $21 \%$ of infected root canal cases. Archaea are prokaryotic microorganisms associated with various pathogenic infections. They can be detected in subgingival plaques with periodontal disease and infected root canals. The role of viruses in endodontic infections is still debatable. The viruses that may be detected in apical periodontitis are human cytomegalovirus and Epstein-Barr virus [5].

Kakehashi et al. (1965) stated that obligate anaerobic, facultative anaerobic, and obligate aerobic bacteria were the main cause of infection in endodontic cases [4]. Secondary infection is a major cause of endodontic treatment failure. It may occur when bacteria penetrate the root canal and adapt to the environment. Based on culture and molecular studies, Enterococcus faecalis is the most commonly found bacteria in endodontically treated teeth and can account for $>90 \%$ of endodontic cases. This suggests that E. faecalis can survive in obturated root canals, even in environments that are not ideal for their growth [1]. E. faecalis is resistant to antibacterial agents, able to survive without nutrients for long periods of time, adaptable to environmental changes with high $\mathrm{pH}$ value, and protected by biofilms. A study by Rocas et al.
(2004) reported that $E$. faecalis is found 9 times more often in cases of endodontic failure than in cases of primary endodontic infections [6].

Sodium hypochlorite $(\mathrm{NaOCl})$ is a widely used disinfectant in endodontic treatment, although the ability of $\mathrm{NaOCl}$ and the concentration used to eliminate E. faecalis is still debatable. However, Kandaswamy and Venkateshbabu (2010) stated that irrigation with $1.3 \%$ and $2.5 \% \mathrm{NaOCl}$ was not effective in eliminating $E$. faecalis on infected dentin cylinders and that $\mathrm{NaOCl}$ effectively eliminated bacteria but was not effective against bacterial endotoxins [7].

Another disinfectant used to eliminate E. faecalis is chlorhexidine (CHX). CHX exerts its antibacterial action by binding to the cell walls of bacteria and causing leakage and lysis of bacterial cells. Ferraz et al. (2007) conducted an in vitro study to demonstrate the ability of CHX to eliminate E. faecalis and found that $2 \% \mathrm{CHX}$ in both gel and solution form is effective in eliminating E. faecalis in the root canal and dentin tubules [8].

It is important that root canal disinfection material not cause irritation of the periapical tissue [2]. $\mathrm{NaOCl}$ and $\mathrm{CHX}$ are irritative to the periapical tissue $[9,10]$. Therefore, to improve biological safety, a natural antibacterial agent was developed. Grape seed extract (GSE) is used to treat various diseases due to its biological activities, such as antioxidant, anticancer, anti-inflammatory, and antibacterial activities [11].

GSE is derived from the seeds of Vitis vinifera and contains proanthocyanidins (PAs), which are phenolic compounds [12]. As an antibacterial agent, the PAs in GSE prevents oral cavity diseases such as periodontitis. PAs in grape seed ethanol extracts reportedly eliminate Streptococcus mutans [13]. In addition, GSE has an inhibitory effect on E. faecalis [14]. Angellina (2013) observed the effect of GSE solution in removing the smear layer in the root canal. The result showed that a $6.5 \%$ GSE removed the smear layer, particularly in the third apical of the root canal. The elimination of the smear layer is believed to be one of the ways to increase the effectiveness of root canal antibacterial agents. It may occur because antibacterial agents can better penetrate the root canal to avoid microleakage [15]. 
This objective of the present study is to observe the antibacterial effect of GSE solution on E. faecalis in biofilm using real-time polymerase chain reaction (RT-PCR), so it can be used as a safe antibacterial agent in endodontics in the future.

\section{METHODS}

This study was conducted at the Institut Pertanian Bogor from June to October 2014. The antibacterial efficacy of GSE solution with 2.9\% tannin against $E$. faecalis biofilm was determined by calculating the amount of bacteria that survived post-exposure of the test material.

GSE solution used was Uzum Cekirdegi Ekstrakti, Immunat, and the tannin level was checked using spectrophotometry. The results showed that the level of tannin in the GSE solution was $2.9 \%$. The $2 \%$ CHX solution used in this study was sold under the name Consepsis (Ultradent). E. faecalis American Type Culture Collection (ATCC) 29212 was obtained from KWIK-STIK ${ }^{\mathrm{T}}$.

E. faecalis ATCC 29212 was evenly applied on brain heart infusion agar (BHIA), incubated at $37^{\circ} \mathrm{C}$ for $24 \mathrm{~h}$, and subsequently inoculated into $10 \mathrm{~mL}$ of sterile saline using an ose needle. The density of the suspension was standardized using McFarland standard 0.5 to obtain $108 \mathrm{CFU} / \mathrm{mL}$. The cellulose nitrate filter membrane (porosity, $0.2 \mu \mathrm{m}$; diameter, $13 \mathrm{~mm}$; Whatman, Whatman International Ltd., Maidstone, UK) on BHIA was subsequently covered with $25 \mu \mathrm{L}$ of bacterial suspension and incubated at $37^{\circ} \mathrm{C}$ for $72 \mathrm{~h}$ under aerobic condition (Fig. 1).

After incubation for $72 \mathrm{~h}$, the membrane was aseptically transferred from BHIA into an Eppendorf tube containing $1 \mathrm{~mL}$ phosphate-buffered saline (PBS) to release bacteria that were not firmly attached to the membrane (planktonic bacteria). Next, each membrane was transferred into three Eppendorf tubes with $1 \mathrm{~mL}$ of PBS (control) solution, three Eppendorf tubes with $1 \mathrm{~mL}$ of GSE solution with $2.9 \%$ tannin content, and three Eppendorf tubes with $1 \mathrm{~mL}$ of $2 \%$ CHX solution and incubated at $37^{\circ} \mathrm{C}$ for $10 \mathrm{~min}$ under aerobic condition.

All membranes of the test and control groups were rinsed 3 times with $1 \mathrm{~mL}$ of PBS to neutralize and stop the activity of the antibacterial agents. Next, the last Eppendorf tube with the membrane was placed on the vortex machine for 2 min to obtain a bacterial suspension. The membrane was then aseptically removed from within the tube (Fig. 2).

Propodium monoazide (PMA) was added to the Eppendorf tube containing $100 \mu \mathrm{L}$ of the bacterial suspension to obtain a final concentration of $100 \mu \mathrm{M}$ and incubated at $4^{\circ} \mathrm{C}$ for $10 \mathrm{~min}$ in a dark room. Subsequently, the Eppendorf tube was horizontally placed on dry ice and exposed to 600 watts of halogen rays for $20 \mathrm{~min}$ at a distance of $20 \mathrm{~cm}$.

Sample homogenization was performed for $10 \mathrm{~s}$ using a vortex machine, and centrifugation was performed at 10,000 rpm for 3 min or until it dissolved. Following centrifugation, the supernatant was discarded using a micro-pipette to leave only the natant inside the microcentrifuge tube. The entire natant was added to $200 \mu \mathrm{L}$ of InstaGene ${ }^{\mathrm{TM}}$ Matrix and homogenized over hot plate using a magnetic stirrer.

Next, the sample was incubated in a water bath at $56^{\circ} \mathrm{C}$ for $30 \mathrm{~min}$ and homogenized using a vortex machine for $10 \mathrm{~s}$. The tube was inserted into the thermoblock at $100^{\circ} \mathrm{C}$ for $8 \mathrm{~min}$. This procedure was repeated 3 times.

Further, the sample was homogenized using a vortex machine for 10 $\mathrm{s}$ and centrifuged at $12,000 \mathrm{rpm}$ for 3 min until the sample solution separated into natant and supernatant. The supernatant was transferred into a new microcentrifuge tube and kept at $4^{\circ} \mathrm{C}$ for $24 \mathrm{~h}$. When in microcentrifuge tubes, natant deposits were still visible, but the supernatant was transferred again into a new microcentrifuge tube and stored at $-20^{\circ} \mathrm{C}$.

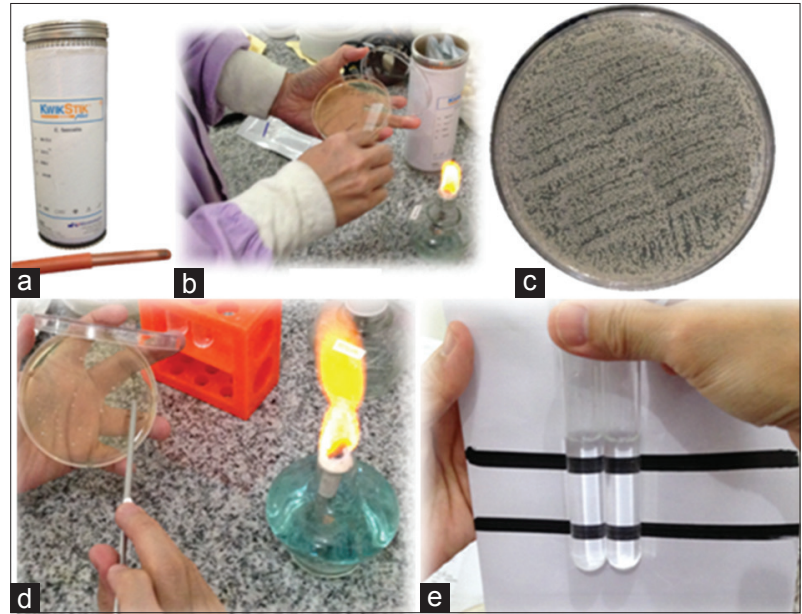

Fig. 1: (a) Enterococcus faecalis American Type Culture Collection (ATCC) $29212^{\mathrm{TM}}$ bacterial preparations, (b) culturing of $E$. faecalis ATCC $29212^{\mathrm{TM}}$ on brain heart infusion agar, (c) colonies of bacteria formed after incubation at $37^{\circ} \mathrm{C}$ for $24 \mathrm{~h}$, (d) collection of bacterial colonies using ose needles to be inserted in a reaction tube containing $\mathrm{NaCl}$, (e) density adjustment according to McFarland standard 0.5

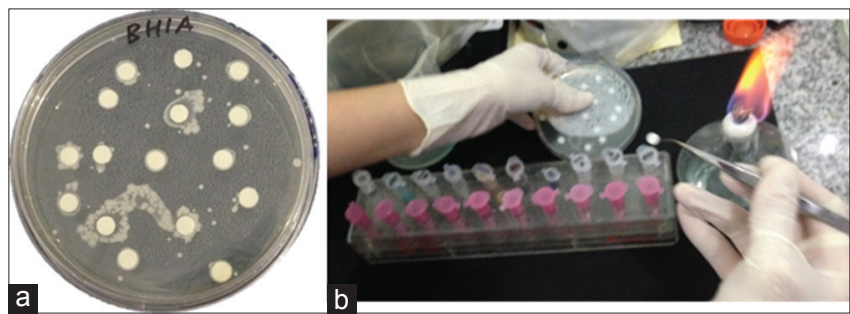

Fig. 2: (a) The biofilm formed after inoculation with $E$. faecalis at $37^{\circ} \mathrm{C}$ for $72 \mathrm{~h}$, (b) bacterial biofilm is washed 3 times with phosphate-buffered saline (PBS) solution and is incubated in $2 \%$ chithexidine, $2 \%$ chlorhexidine, and PBS solution, which was used as a control, at $37^{\circ} \mathrm{C}$ for $10 \mathrm{~min}$

Primers EF Gro ES-F and EF Gro ES-R were diluted using TE buffer. The ratio of EF Gro ES-F and EF Gro ES-R was 9:1. The diluted primers were homogenized using a vortex machine followed by a spin down machine. Next, the PCR mix was made as follow: (1) $1.5 \mathrm{~mL}$ microcentrifuge tubes were coated with aluminum foil; (2) volume of PCR mix was calculated by multiplying each mixture by the number of samples to be processed using RT-PCR. The required mixtures were $10 \mu \mathrm{L}$ of Power SYBR $®$ Green PCR Master Mix, $2 \mu \mathrm{L}$ of universal primer 357F, $2 \mu \mathrm{L}$ of universal primer $907 \mathrm{R}$, and $2 \mu \mathrm{L}$ of nuclease-free water, and (3) all PCR mix materials were combined in $1.5 \mathrm{~mL}$ microcentrifuge tubes that were coated with aluminum foil. Next, the mix was incorporated into the MicroAMP ${ }^{\mathrm{TM}}$ Fast reaction tubes with as much as $16 \mu \mathrm{L}$ and added with $4 \mu \mathrm{L}$ DNA samples. Finally, the mixture was homogenized using a micro-pipette.

MicroAmp ${ }^{\text {TM }}$ Fast reaction tubes (8 tubes/strip) were covered with a MicroAmp ${ }^{\mathrm{TM}}$ Optical 8-Cap Strip for asepsis. PCR well plate was inserted into the step-one RT-PCR System (Applied Biosystems) and the parameters were adjusted as needed. RT-PCR quantitative cycle for total bacteria and preheat activation was performed at $95^{\circ} \mathrm{C}$ for $3 \mathrm{~min}$, followed by denaturation at $95^{\circ} \mathrm{C}$ for $15 \mathrm{~s}$ ( 40 cycles), primary annealing at $55^{\circ} \mathrm{C}$ for $30 \mathrm{~s}$, and elongation at $72^{\circ} \mathrm{C}$ for $30 \mathrm{~s}$. Subsequently, the results were read on a computer screen (Fig. 3).

Data obtained were analyzed using SPSS 20.0 software. The number of viable E. faecalis from the control and test groups was analyzed for normality and homogeneity. One-way ANOVA was performed if the data 


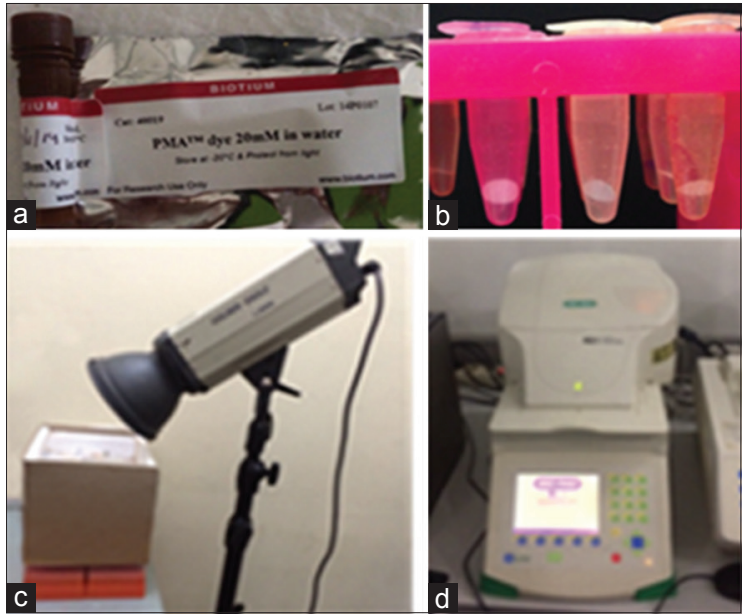

Fig. 3: (a and b) Addition of propodium monoazide and incubation in dark room, (c) exposure to 600 watts of halogen rays for $20 \mathrm{~min}$, (d) detection and quantification of DNA of Enterococcus faecalis using real-time polymerase chain reaction

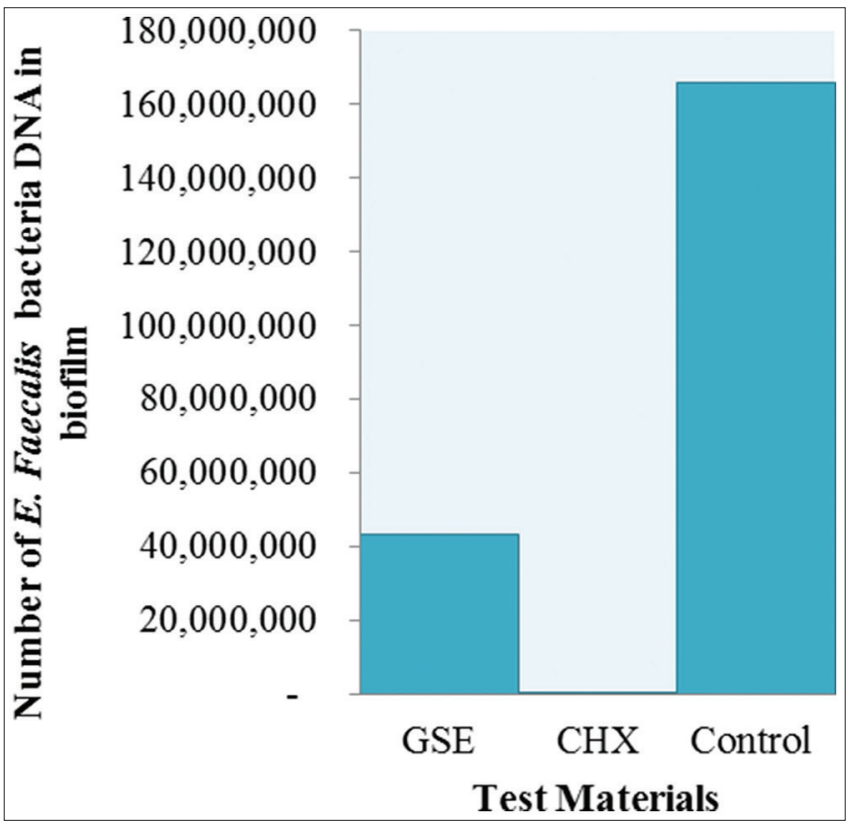

Fig. 4: Comparison of the mean DNA count of Enterococcus faecalis in biofilm (CFU/mL) in the GSE, CHX, and control groups. GSE: Grape seed extract, CHX: 2\% Chlorhexidine

distribution was normal and homogeneous. Multiple comparison test with post hoc least significant difference was performed when there was a significant difference. Statistical analysis using Kruskal-Wallis non-parametric test and post hoc Mann-Whitney U-test was performed if the data distribution was not normal or homogeneous. $p \leq 0.05$ was considered statistically significant.

\section{RESULTS}

The results of this research quantified viable E. faecalis after exposure to GSE solution with $2.9 \%$ tannin and $2 \%$ CHX for $10 \mathrm{~min}$. Non-parametric Kruskal-Wallis test was performed to assess the significance of bacterial yield because the data distribution was not homogeneous (Table 1).

The highest mean and standard deviation (SD) values were found in the control group, followed by the GSE and CHX groups. However, the $\mathrm{SD}$ values in the CHX group were greater than the mean values in the CHX group. Therefore, although the CHX group showed the lowest
Table 1: Mean of $E$. faecalis DNA count in biofilm after mixed with test material $(\mathrm{CFU} / \mathrm{mL})$

\begin{tabular}{lllll}
\hline Test material & $\mathbf{n}$ & Minimum & Maximum & Mean \pm SD \\
\hline GSE & 3 & $0.41 \times 10^{8}$ & $0.46 \times 10^{8}$ & $0.43 \times 10^{8} \pm 0.02 \times 10^{8}$ \\
CHX & 3 & $0.03 \times 10^{4}$ & $2.32 \times 10^{4}$ & $0.86 \times 10^{4} \pm 1.29 \times 10^{4}$ \\
Control & 3 & $1.33 \times 10^{8}$ & $2.11 \times 10^{8}$ & $1.66 \times 10^{8} \pm 0.40 \times 10^{8}$ \\
\hline
\end{tabular}

GSE: Grape seed extract, CHX: $2 \%$ Chlorhexidine, E. faecalis: Enterococcus faecalis

Table 2: The significance of the antibacterial efficacy of each test group

\begin{tabular}{lll}
\hline Test group & CHX & Control \\
\hline GSE & $0.05^{*}$ & $0.05^{*}$ \\
CHX & & $0.05^{*}$ \\
\hline
\end{tabular}

*Significance level of $\mathrm{p} \leq 0.05$ using post hoc Mann-Whitney U-test analysis. GSE: Grape seed extract, CHX: 2\% Chlorhexidine

mean of bacterial DNA, the data in the CHX group had the highest data deviation.

Fig. 4 shows the mean number of $E$. faecalis DNA in the biofilm in each test group. The highest mean DNA count was in the control group, followed by the GSE and CHX groups. Therefore, 2\% CHX showed the highest antibacterial efficacy.

The difference in the amounts of DNA between the GSE and CHX groups, GSE and control groups, and CHX and control groups was significant ( $p=0.05$; Table 2).

\section{DISCUSSION}

The present study analyzed the antibacterial efficacy of GSE with $2.9 \%$ tannin against $E$. faecalis biofilm and compared the antibacterial efficacy of GSE solution with that of $2 \%$ CHX. The results of this study are consistent with that of the previous research by Angellina (2013) that analyzed the antibacterial efficacy of GSE as a root canal irrigation solution for smear-layer cleaning in a third apex of the root canal wall because the GSE solution was believed to increase the collagen cross-totooth strength [15]. The background of this study refers to the findings of Mageshwaran et al. (2012), who found that PAs in GSE provided antibacterial efficacy against E. faecalis in root canals [13].

At present, $2 \% \mathrm{CHX}$ is the most effective root canal irrigation solution to remove E. faecalis; therefore, CHX was used as a standard in the present study. This is consistent with the Schafer and Bossmann findings, in 2005 , which suggest that $2 \%$ CHX is effective against Gram-positive bacteria, such as E. faecalis [16].

E. faecalis ATCC 29212 with zero passage was used in the present study. The purpose of using zero passage is to avoid the risk of contamination in the subculture, errors during displacement and labeling, and occurrence of phenotypic changes or mutations that may occur during subculturing.

E. faecalis biofilm was used because there are several studies that prove that bacteria contained in a biofilm can withstand antibacterial agents compared to bacteria in planktonic form. The bacteria in the biofilm are attached to the root canal wall, isthmus, lateral root canal, and dentin tubules, thereby making it difficult to remove them with instrumentation alone [1].

The biofilm of E. faecalis was formed on cellulose nitrate membrane to obtain standardized growth for accurate antibacterial efficacy assessment [17].

RT-PCR was used to quantify the DNA. In conventional PCR, the detection and quantification of the amplified product are done at the last reaction 
after the last PCR cycle, whereas, in RT-PCR, the amplicon is assessed at each cycle by analyzing the exponential phase of the reaction. PCR is one of the best methods in molecular biology (DNA-based) due to its high specificity, sensitivity, and speed [18]. Alvarez et al. (2013) suggested that the PCR method is widely developed because it is more sensitive to bacteria than conventional culture techniques. Conventional bacterial culture methods only detect bacterial cells that form colonies on nutrient media but cannot detect dead bacterial cells, viable but nonculturable (VBNC) bacterial cells, and bacteria that require special media for growth. According to Eswar et al. (2013), RT-PCR is a suitable method for detecting E. faecalis because E. faecalis has VBNC bacterial cells [19].

One disadvantage of PCR is that it cannot distinguish between living and dead cells; therefore, the DNA of dead cells is also readable on the PCR cycle. Therefore, this study used PMA in the sample. PMA is a propidium iodide (PI) derivative; PI colors dead cells by penetrating bacterial cell membranes that have lost their integrity. PI binds to bacterial DNA and emits fluorescence at certain wavelengths. This DNA modification renders it inactive during PCR, thereby differentiating between living cells and dead cells in the final quantitative results [20].

The presence of antibacterial efficacy in the GSE solution had been suggested by previous authors. According to Mageshwaran et al. (2012), GSE solution can inhibit the growth of E. faecalis [13]. In the group with a combination of CHX, calcium hydroxide, and GSE solutions showed a smaller zone of inhibition than the control group using agar diffusion methods. However, this research was different from the present study in terms of $E$. faecalis preparation and examination methods. Mageshwaran et al. (2012) used E. faecalis in planktonic form and the diffusion method, whereas the present study used E. faecalis in the form of biofilm and real-time PCR. To the best of our knowledge, no other study has been conducted using pure GSE solution, as done in this study.

The antibacterial mechanism of GSE is believed to be related to its chemical structure. PA interacts with proteins present in the bacterial cell membrane, resulting in the following three actions: The destruction of cell membranes, impairment of the proton motive force process, and inhibition of cell membrane enzymatic activity $[21,22]$. In addition, Xia et al. (2010) stated that the core structure of 3,4,5-trihydroxyphenyl that is found in the epigallocatechin monomer has a role in antibacterial action. The hydroxyl group and the double bonds present in this core structure bind proteins to the cell wall. Therefore, the antibacterial efficacy of the phenol compound depends on the number of hydroxyl groups and the degree of polymerization [23]. While the antibacterial mechanisms of CHX are related to positive molecules, these positive molecules can bind to negative ions, both in bacterial cell walls and in dentine hydroxyapatite. Bonding of bacterial cell walls causes nucleic acid leakage and bacterial cell lysis, whereas bonding in dentine causes CHX to be gradually released at a therapeutic level, which is known as the substantive nature [16]. GSE antibacterial properties are not proportional to $\mathrm{CHX}$ antibacterial properties due to the differences in their antibacterial mechanisms.

In this study, the antibacterial efficacy of GSE with $2.9 \%$ tannin could not exceed that of CHX because it is a natural material. Nevertheless, GSE has the advantage of good biological safety. GSE had been widely used as a health supplement due to its antioxidant properties [21]. In addition, Yamakoshi et al. (2002) reported that GSE is not mutagenic or toxic in studies conducted in mice [24]. This very low toxicity is important in endodontics because it can stimulate tissue regeneration and tissue healing.

The GSE solution used in this study contained 2.9\% tannin, which is $<5 \%$ concentration used by Mageshwaran et al. (2012). They used GSE preparations in the form of powder mixed with the water solvent. In addition, the GSE solution was combined with $2 \%$ CHX and calcium hydroxide. Differences in the preparations caused differences in the results obtained between theirs and the present study. In the current study, the antibacterial efficacy of GSE solution compared with 2\% CHX is not as good as that in previous studies.

\section{CONCLUSION}

The PAs (tannin) $2.9 \%$ in GSE provides antibacterial efficacy to E. faecalis biofilm characterized by decreasing the DNA count in E. faecalis biofilm after exposure to GSE. The antibacterial efficacy of GSE is lower than that of $2 \% \mathrm{CHX}$, possibly because the GSE solution is a natural ingredient and to match the antibacterial efficacy of $2 \% \mathrm{CHX}$, a high concentration of chemicals would be required. Although GSE has a lower antibacterial efficacy than $2 \%$ CHX, it is biologically safe and has potential as a root canal irrigation material

\section{CONFLICTS OF INTEREST}

There are no conflicts of interest to declare.

\section{REFERENCES}

1. Siqueira J, Rocas I. Microbiology and treatment of endodontic infections. In: Hargreaves K, Cohen S, editors. Cohen's: Pathways of the Pulp. St. Louis: Mosby Elsevier; 2011. p. 559-68.

2. Peters O, Peters C. Cleaning and shaping of root canal system. In: Hargreaves K, editor. Cohen's: Pathways of the Pulp. St. Louis: Mosby Elsevier; 2011. p. 311-2.

3. Haapasalo M, Shen Y, Qian W, Gao Y. Irrigation in endodontics. Dent Clin North Am 2010;54:291-312.

4. Kakehashi S, Stanley HR, Fitzgerald RJ. The effect of surgical exposure of dental pulps in germ free and conventional laboratory rats. Oral Surg 1965;20:340-9.

5. Siqueira J, Rocas I. Primary Endodontic Infections. In: Siqueira JF, editor. Treatment of Endodontic Infections. Berlin: Quintessence Publishing; 2011. p. 115-7.

6. Stuart CH, Schwartz SA, Beeson TJ, Owatz CB. Enterococcus faecalis: Its role in root canal treatment failure and current concepts in retreatment. J Endod 2006;32:93-8.

7. Kandaswamy D, Venkateshbabu N. Root canal irrigants. J Conserv Dent 2010;13:256-64

8. Ferraz CC, Gomes BP, Zaia AA, Teixeira FB, Souza-Filho FJ. Comparative study of the antimicrobial efficacy of chlorhexidine gel, chlorhexidine solution and sodium hypochlorite as endodontic irrigants. Braz Dent J 2007;18:294-8.

9. Gernhardt CR, Eppendorf K, Kozlowski A, Brandt M. Toxicity of concentrated sodium hypochlorite used as an endodontic irrigant. Int Endod J 2004;37:272-80.

10. Onçağ O, Hoşgör M, Hilmioğlu S, Zekioğlu O, Eronat C, Burhanoğlu D, et al. Comparison of antibacterial and toxic effects of various root canal irrigants. Int Endod J 2003;36:423-32.

11. de la Iglesia R, Milagro FI, Campión J, Boqué N, Martínez JA. Healthy properties of proanthocyanidins. Biofactors 2010;36:159-68.

12. La VD, Howell AB, Grenier D. Cranberry proanthocyanidins inhibit MMP production and activity. J Dent Res 2009;88:627-32.

13. Mageshwaran T, Ebenezar AR, Madhanamadhubala M, Kavitha S, Mahalaxmi S. Counteraction of reactive oxygen species and determination of antibacterial efficacy of proanthocyanidin and lycopene when mixed with calcium hydroxide and chlorhexidine mixture: An in vitro comparative study. J Conserv Dent 2012;15:337-41.

14. Ranjitha CY, Priyanka S, Deepika R, Rani GP. Antimicrobial activity of grape seed extract. World J Pharm Pharm Sci 2014;3:1483-8.

15. Angellina AN. Potential of Grape Seed Extract as Root Canal Irrigation Solution in Cleaning the Smear Layer. Thesis. Jakarta: Universitas Indonesia; 2013.

16. Ryan S. Chlorhexidine as a canal irrigant: A review. Compend Contin Educ Dent 2010;31:338-42.

17. Chai WL, Hamimah H, Cheng SC, Sallam AA, Abdullah M. Susceptibility of Enterococcus faecalis biofilm to antibiotics and calcium hydroxide. J Oral Sci 2007:49:161-6.

19. Life Technologies. Real-Time PCR Handbook. Life Technologies; 2012.

20. Eswar K, Venkateshbabu N, Rajeswari K, Kandaswamy D. Dentinal tubule disinfection with $2 \%$ chlorhexidine, garlic extract, and calcium hydroxide against Enterococcus faecalis by using real-time polymerase chain reaction: In vitro study. J Conserv Dent 2013;16:194-8.

21. Alvarez G, González M, Isabal S, Blanc V, León R. Method to quantify live and dead cells in multi-species oral biofilm by real-time PCR with propidium monoazide. AMB Express 2013;3:1. 
22. PerumallaA, Hettiarachchy N. Green tea and grape seed extracts potential applications in food safety and quality. Food Res Int 2011;44:827-39

23. Sivarooban T, Hettiarachchy N, Johnson M. Physical and antimicrobial properties of grape seed extract, nisin and EDTA incorporated soy protein edible biofilm. Food Res Int 2008;41:781-5.
24. Xia EQ, Deng GF, Guo YJ, Li HB. Biological activities of polyphenols from grapes. Int J Mol Sci 2010;11:622-46.

24. Yamakoshi J, Saito M, Kataoka S, Kikuchi M. Safety evaluation of proanthocyanidin-rich extract from grape seeds. Food Chem Toxicol 2002;40:599-607. 